\title{
Revisit Intention Wisatawan di Taman Tematik Kota Bandung
}

\author{
Vany Octaviany \\ Telkom University \\ vany@tass.telkomuniversity.ac.id \\ Dwiesty Dyah Utami \\ Sekolah Tinggi Pariwisata Bandung \\ dwiesty.dyah@yahoo.com
}

\begin{abstract}
One of the tourist attraction that is in interest in the city of Bandung is a theme park. Bandung thematic park managers as one tourist attraction that can attract tourists to continue to come to the city of Bandung need to understand how to make the tourists feel satisfied and come back for a tour in the city of Bandung, considering now many areas in Indonesia that develop shopping tourist attractions and culinary that has been popular by tourists in the city of Bandung. Therefore, the researcher raised the factor of tourist intention or revisit of tourist intention in Bandung thematic theme park as research theme. This research is descriptive research. Research method used in this research is explanatory survey, the sample to be studied is a number of 150 people by using systematic random sampling Based on the results of research revisit intention in Bandung Thematic Park has a high assessment. It shows that the tourists who come to the theme parks of Bandung City are satisfied with thematic parks they visit, so intend to re-visit and have the desire to recommend thematic parks Bandung to others.
\end{abstract}

Keywords-Component; Theme Park; Revisit Intention; Bandung

\section{Pendahuluan}

Kota Bandung sebagai ibukota provinsi Jawa Barat dilihat dari jumlah penduduk merupakan merupakan kota terbesar ketiga di Indonesia setelah Jakarta dan Surabaya. Dalam beberapa tahun terakhir, Sebagai salah satu destinasi wisata, Kota Bandung yang juga dikenal sebagai kota kreatif yang banyak melakukan inovasi dalam pengembangan produk wisata yang akan ditawarkan kepada wisatawan. Salah satu atraksi wisata yang sedang diminati wisatawan adalah taman-taman kota, festival kuliner, dan komunitas anak muda. Hal tersebut menjawab tingginya kebutuhan wistaawan terhadap produk wisata Kota Bandung.

Diantara inovasi yang dilakukan Kota bandung, salah satu produk wisata yang banyak menarik perhatian wisatawanadalah taman tematik. Taman tematik merupakan taman dengan beragam tema yang menarik serta suasana yang artistik. Tama tematik menjadi pilihan wisatawan untuk menghabiskan waktu luangnya karena tidak memerlukan biaya untuk dapat menikmatinya dan merupakan ruang terbuka yang nyaman untuk disinggahi. Penyediaan taman tematik di lingkungan hunian Kota Bandung telah mengalami perubahan menjadi taman dengan skala pelayanan kota dan menjadi penarik utama pergerakan baru sebagai ruang publik yang difungsikan sebagai sumber hiburan dan rekreasi bagi masyarakat kota dengan desain fisik dan fasilitas yang aktraktif. Ari, Zulkaidy dan Pratiwi (2016:163).

Menurut Leon Krier (1992), kota yang baik adalah kota yang diatur berdasarkan integrasi kebutuhan yang memadai di tiap lingkungan kawasan. keberadaan taman tematik di Kota Bandung merupakan sebuah sarana rekreasi dengan tujuan melengkapi fasilitas kehidupan yang terintegrasi di dalam satu kawasan. Sehingga jarak, perpindahan, konsumsi waktu dan energi dapat direduksi demi kelangsungan dalam penuhan kebutuhan hidup yang baik. Menurut Yodia dan Sudarma (2015: 43) untuk dapat menghadirkan ruang pubik kota yang atraktif maka diciptakanlah taman tematik kota dengan skala yang lebih kecil dengan atraksi kegiatan hanya fokus pada tema tertentu dan dapat diakses dengan gratis dan tidak terbatas. Taman bertema dapat diidentifikasi sebagai cerminan akan karakter manusia yang membutuhkan ruang untuk meluapkan emosi dan keinginan akan ruang yang atraktif dan mampu mewadahi kebutuhan akan tempat yang mampu memberikan hiburan yang variatif. Lucas dalam Ari, Zulkaidy dan Pratiwi (2016:163). 
Taman tematik yang terdapat di Kota Bandung antara lain taman gesit, taman film, taman vanda, alun-alun kota bandung, balai kota bandung, taman pasupati, taman fitnes, taman lansia, taman superhero, taman pustaka bunga, teras cikapundung BBWS, dan Music park centrum. Taman tematik Kota Bandung sebagai salah satu daya tarik wisata yang dapat menarik minat wisatawan untuk terus datang ke Kota Bandung perlu memahami bagaimana cara agar wisatawan merasa puas dan datang kembali untuk berwisata di Kota Bandung mengingat kini banyak daerah di Indonesia yang mengembangkan atraksi wisata belanja dan kuliner yang selama ini diminati wisatawan di Kota Bandung. Oleh karena itu, peneliti mengangkat faktor niat wisatawan atau revisit intention wisatawan di taman tematik Kota Bandung sebagai tema penelitian. Adapun rumusan masalah dalam penelitian ini adalah bagaimana gambaran revisit intention wisatawan di Taman Tematik Kota Bandung, tujuan penelitian adalah untuk mengetahui revisit intention wisatawan di Taman Tematik Kota Bandung

\section{KAJIAN PUSTAKA}

\section{A. Taman Kota}

Menurut Ditjen Cipta Karya (1997) kota adalah merupakan permukiman yang berpenduduk relative besar, luas areal terbatas, pada umumnya bersifat nonagraris, kepadatan penduduk relatif tinggi, tempat sekelompok orang dalam jumlah tertentu dan bertempat tinggal dalam suatu wilayah geografis tertentu, cenderung berpola hubungan rasional, ekonomis, dan individualistis.

Laurie (1986:9) mengatakan bahwa taman adalah sebidang lahan berpagar yang digunakan untuk mendapatkan kesenangan, kegembiraan, dan kenyamanan. Sedangkan Gallion dan Eisner (1994) Taman kota merupakan transisi antara perkembangan kota dan daerah pedesaan, yang terletak di luar konsentrasi penduduk. Taman kota dibentuk sebagai penyekat hijau untuk memisahkan berbagai penggunaan lahan dalam kota.

Menurut Nazzaruddin (1994: 29), taman adalah sebidang lahan terbuka dengan luasan tertentu di dalamnya ditanam pepohonan, perdu, semak dan rerumputan yang dapat dikombinasikan dengan kreasi dari bahan lainnya. Umumnya dipergunakan untuk olahraga, bersantai, bermain dan sebagainya. Jenis taman terbagi menjadi dua, yaitu:

\section{Taman publik aktif}

Taman publik aktif adalah taman yang memiliki fungsi sebagai tempatbermain dan olahraga, dilengkapi dengan elemen-elemen pendukung taman bermain dan lapangan olahraga, contohnya: alun-alun, central park di New York.

\section{Taman publik pasif}

Taman publik pasif maksudnya adalah taman ini hanya sebagai elemen estetis saja, sehingga kebanyakan untuk menjaga keindahan tanaman di dalam taman tersebut akan dipasang pagar di sepanjang sisi luar taman. Contohnya: Bundestagen Park, Cologne Germany.

\section{B. Taman Tematik}

RTH perkotaan terdiri dari taman kota. Sedangkan taman tematik merupakan bagian dari taman kota. Taman tematik hanya merupakan istilah untuk taman yang sengaja dibuat oleh gagasan walikota Bandung yang baru yaitu Ridwan Kamil. Semenjak kepengurusannya walikota periode 2013-2018 ini, mulai akhir 2013 lalu Ridwan kamil telah membuat konsep taman tematik. Istilah taman tematik ini bertujuan supaya dapat membedakan antara taman yang satu dengan taman yang lainnya. Taman tematik adalah taman yang memiliki fungsi yang hampir sama dengan selayaknya taman0taman kota lain, namun yang mebedakan adalah konsep dari tiap taman tersebut. Konsep tersebut masing-masing telah memiliki tema (Ilmiajayanti dan Dewi, 2015:23).

\section{Revisit Intention}

Menurut Park (2010) Minat beli ulang adalah sama pentingnya sebagai indikator kunci dari loyalitas. Miller, Glawter, dan Primban dalam Basiya dan Rozak (2012) menambahkan bahwa Purchase intention adalah keadaan mental seseorang yang mencerminkan rencana untuk melakukan beberapa tindakan dalam jangka waktu tertentu. Definisi ini diasumsikan sebagai anteseden langsung dari perilaku. Penerapannya dalam riset terhadap definisi purchases intention adalah pelanggan akan melakukan tindakan pembelian kembali diwaktu yang akan datang sebagai respon langsung dari perilaku paska pembelian dalam jangka waktu tertentu. Hasan (2013:131). Pada dasarnya minat beli ulang merupakan suatu perilaku seseorang yang disebabkan oleh perilaku masa lalu (pengalaman konsumsi) yang secara langsung mempengaruhi minat untuk mengkonsumsi ulang pada waktu yang akan datang.

Menurut Lin and Morais dalam Lin (2012), ada tiga dimensi dari revisit intention, yaitu:

1. Intention to revisit atau niat untuk berkunjung ulang, 
2. Intention to recommend atau niat untuk merekomendasikan, dan

3. Resistance to change atau perlawanan untuk perubahan.

Menurut Baker dalam Crompton dalam Chung-Hslen Lin (2012) terdapat dua dimensi revisit intention, yaitu:

1. Intention to Recommend (Keinginan untuk merekomendasikan kepada orang lain)

2. Intention to Revisit (Keinginan untuk kembali berkunjung)

Zeithaml et al (1996) dalam Grewal et al (2008:428), yang menyebutkan juga bahwa terdapat dua dimensi pada revisit intention, yaitu:

1. Keinginan untuk merekomendasikan kepada orang lain

2. Keinginan untuk kembali berkunjung

\section{Metode Penelitian}

Penelitian ini merupakan penelitian deskriptif. metode penelitian yang digunakan pada penelitian ini adalah explanatory survey. Berdasarkan sumbernya data penelitian yang digunakan terdiri dari data primer yaitu data responden, data tanggapan revisit intention wisatawan di taman tematik Kota Bandung. Dalam Penelitian sample yang akan diteliti adalah sejumlah 150 orang yang berkunjung ke taman tematik Kota Bandung. Dengan tehnik pengambilan sample menggunakan systematic random sampling. Tehnik pengumpulan data dilakukan dengan cara wawancara, kuesioner/angket, observasi dan studi literatur. Alat ukur yang digunakan untuk membuat pertanyaan-pertanyaan pada kuisioner yaitu dengan menggunakan skala likert.

\section{Hasil PENELITIAN DAN PEMBahasan}

Berdasarkan hasil survey yang dilakukan pada 150 orang responden yang mengunjungi taman tematik Kota Bandung, dapat diketahui bahwa $70 \%$ dari wisatawan yang datang merupakan kelompok usia dewasa. Rata-rata jenis pekerjaan wisatawan adalah kalangan pelajar/mahasiswa.Sebagian besar wisatawan yang datang ke taman tematik Kota Bandung merupakan penduduk Kota Bandung. Hal tersebut menunjukan bahwa tujuan walikota Bandung, Bpk Ridwan kamil dalam penyediaan ruang terbuka hijau bagi warga Kota Bandung tepat sasaran, dimana warga Kota Bandung memanfaatkan keberadaan taman-taman kota yang dibangun untuk berekreasi. Akan tetapi di sisi lain diketahui bahwa wisatawan asal daerah luar Kota Bandung masih sedikit yang berminat berkunjung ke Taman Tematik Kota Bandung. Padahal taman tematik merupakan salah satu daya tarik wisata yang dapat menjadi pilihan bagi wisatawan yang datang ke Kota Bandung, yang mulai merasa bosan dengan atraksi wisata yang ditawarkan seperti wisata kuliner dan wisata belanja. Berdasarkan hasil pengolahan data, dapat diketahui bahwa $68 \%$ wisatawan melakukan kunjugan ulang. Hal tersebut menunjukan bahwa wisatawan merasa puas dengan produk wisata yang ditawarkan taman tematik Kota Bandung. 75\% wisatawan datang berkunjung selama kurang lebih 1-2jam. Sedangkan $55 \%$ wisatawan menyatakan bahwa fasilitas yang tersedia di taman tematik Kota Bandung sudah baik.Hal tersebut menunjukan bahwa wisatawan merasa puas dengan kunjungan terdahulu, akan tetapi waktu kunjungan yang sebentar menunjukan bahwa fasilitas pendukung di taman tematik Kota Bandung perlu ditambah agar wisatawan dapat melakukan lebih banyak aktivitas wisata.

Penilaian wisatawan terhadap tingkat kenyamanan saat berada di taman tematik Kota Bandung, 69\% wisatawan menyatakan nyaman saat berwisata di taman tematik Kota Bandung, $45 \%$ wisatawan menyatakan bahwa tingkat keamanan di taman Kota Bandung cukup baik. Hal tersebut menunjukan bahwa wisatawan merasa nyaman dengan atmosfir yang dirasakan saat berada di taman tematik Kota Bandung, saat berada di taman tematik Kota Bandung wisatawan dapat besantai, menghirup udara segar, berfoto, dan menikmati fasilitas yang tersedia. Walaupun merasa nyaman, akan tetapi tingkat keamanan perlu diperhatikan oleh Pemkot Kota Bandung. Hal tersebut dikarenakan wisatawan hampir tidak pernah menemukan petugas keamanan yang berjaga di sekitar lokasi taman tematik Kota Bandung. Penilaian terhadap kemudahan mencapai lokasi dan ketersediaan transportasi umum untuk menuju lokasi, wisatawan menilai bahwa aksesibilatas menuju taman tematik Kota Bandung mudah diakses yaitu sebesar $90 \%$. Hal tersebut dikarenakan, taman tematik sengaja dibangun di beberapa titik pusat kota 
TABel 1. KeInginan Untuk BeRKunJung KembaLI

\begin{tabular}{|c|c|c|c|c|c|c|c|}
\hline \multirow{2}{*}{ No } & \multirow{2}{*}{ Pernyataan } & \multicolumn{6}{|c|}{ Alternatif Jawaban } \\
\hline & & ST & $\mathrm{T}$ & CT & $\mathrm{R}$ & SR & Total \\
\hline 1 & $\begin{array}{l}\text { Keinginan untuk berkunjung kembali ke Taman Tematik Kota } \\
\text { Bandung }\end{array}$ & $52 \%$ & $44 \%$ & $2 \%$ & $2 \%$ & $0 \%$ & 100 \\
\hline 2 & $\begin{array}{l}\text { Kemungkinan untuk kembali lagi di masa yang akan datang ke ke } \\
\text { Taman Tematik Kota Bandung }\end{array}$ & $50 \%$ & $48 \%$ & $1 \%$ & $1 \%$ & $0 \%$ & 100 \\
\hline & Total & & & & & & 100 \\
\hline
\end{tabular}

Sumber Hasil Pengolahan Data (2017)

Berdasarkan survey yang dilakukan terhadap 150 pengunjung taman tematik Kota Bandung, dapat diketahui bahwa wisatawan ingin melakukan kunjungan ulang ke taman tematik Kota Bandung, yaitu 52\% menyatakan keinginan tersebut sangat tinggi. Sebanyak 50\% wisatawan menyatakan sangat tertarik untuk kembali lagi di masa yang akan datang ke Taman Tematik Kota Bandung. Hal tersebut menunjukan bahwa wisatawan merasa puas dengan kunjungan mereka sebelumnya. Terdapat beberapa hal yang perlu ditingkatkan oleh pengelola Saat berkunjung ke taman tematik Kota Bandung seperti ketersediaan fasilitas umum dan fasilitas wisata. Fasilitas umum yang dinilai kurang baik adalah toilet umum dan kantin. Toilet menjadi kebutuhan dasar wisatawan. Pada beberapa taman tematik terdapat toilet yang dapat digunakan oleh wisatawan, akan tetapi kondisinya kurang terawat dengan baik, sehingga terkadang tercium bau yng kurang sedap. Begitupula dengan kantin. Wisatawan kesulitan menemukan penjual makanan saat mereka menikmati taman tematik Kota Bandung. Pada beberapa taman tematik terdapat kantin penjual makanan yang menjajakan beberapa jenis makanan, akan tetapi mereka tidak tertata dengan baik, sehingga terkesan semrawut dan meyebabkan wisatawan terkadang enggan untuk membeli. Selain fasilitas, ketersediaan pusat informasi dan keamanan juga perlu diperhatikan. Wisatawan kesulitan menemukan pusat informasi atau petugas yang dapat dimitai keterangan terkait atraksi wisata yang disediakan, selain itu faktor keamanan juga perlu diperhatikan. Tingginya jumlah kunjungan wisatawan terutama pada hari libur perlu mendapatkan pengawasan dari petugas keamanan. Wisatawan tidak pernah menemukan petugas yang berjaga di lokasi taman tematik Kota Bandung.

Tabel 2. KeIngInAn UntuK MereKomendasiKan KePAda ORANG LAIN

\begin{tabular}{|c|c|c|c|c|c|c|c|}
\hline \multirow{2}{*}{ No } & \multirow{2}{*}{ Pernyataan } & \multicolumn{6}{|c|}{ Alternatif Jawaban } \\
\hline & & ST & $\mathrm{T}$ & CT & $\mathrm{R}$ & SR & Total \\
\hline 1 & $\begin{array}{l}\text { Keinginan untuk merekomendasikan kepada teman, keluarga dan } \\
\text { kerabat untuk berkunjung ke Taman Tematik Kota Bandung }\end{array}$ & $51 \%$ & $45 \%$ & $2 \%$ & $2 \%$ & $0 \%$ & 100 \\
\hline 2 & $\begin{array}{l}\text { Keinginan untuk membicarakan hal hal positif mengenai Taman } \\
\text { Tematik Kota Bandung }\end{array}$ & $48 \%$ & $50 \%$ & $1 \%$ & $1 \%$ & $0 \%$ & 100 \\
\hline & Total & & & & & & 100 \\
\hline
\end{tabular}

Sumber Hasil Pengolahan Data (2017)

Berdasarkan hasil pengolahan data, dapat diketahui bahwa wisatawan sebagian besar menyatakan akan merekomendasikan kepada teman, keluarga dan kerabat untuk berkunjung ke taman tematik Kota Bandung. Hal tersebut menunjukan bahwa wisatawan merasa puas dengan produk wisata yang ditawarkan taman tematik Kota Bandung. Fornell (1992) dalam New Gaik Ling (2012:5) menyatakan bahwa konsumen atau pelanggan yang puas akan melakukan kunjungan ulang pada waktu yang akan datang dan memberitahukan kepada orang lain atas jasa yang dirasakan. Jika konsumen atau wisatawan sudah merasa senang dengan perjalanannya, tidak menutup kemungkinan bahwa mereka akan melakukan kunjungan ulang (revisit intention) pada objek wisata yang telah mereka datangi sebelumnya

\section{KESIMPULAN}

Berdasarkan paparan sebelumnya maka diketahui bahwa pengunjung Taman Tematik Kota Bandung mayoritas memiliki keinginan untuk mengunjungi kembali taman-taman tersebut. Selain itu juga mereka berkeinginan untuk memberikan rekomendasi kepada orang lain. Beberapa hal yang perlu diperbaiki dari taman-taman tematik di Kota Bandung menyangkut fasilitas umum dan fasilitas wisatanya.

\section{DAFTAR RUJUKAN}

Ali, Hasan. (2013). Marketing dan KasusKasus Pilihan. Yogyakarta. CAPS. (Center For Academic Publishing Service). 
Anonim (1998), Tata Cara Survai dan Pengkajian Demografi dan Ketatakotaan, Departemen Pekerjaan Umum, Ditjen Cipta Karya.

Basiya, R., dan Rozak, H. A.. (2012). Kualitas Daya Tarik Wisata, Kepuasan Dan Niat Kunjungan Kembali Wisatawan Mancanegara Di Jawa Tengah. Jurnal Ilmiah Dinamika Kepariwisataan, XI(2), $1-12$

Freska Ilmiajayanti dan Diah Intan Kusumo Dew. (2015). Persepsi Pengguna Taman Tematik Kota Bandung Terhadap Aksesibilitas Dan Pemanfaatannya. ruang, volume 1 nomor 1, 2015, 21-30, p-issn 1858-3881; e-issn 2356-0088, http://ejournal2.undip.ac.id /index.php/ruang, ruang (vol.1) no. 1, 2015, 21 - 30doi: http://dx.doi.org/ 10.14710/ruang.1.4.21-30

Gallion, B. Arthur dan Eisner Simon. (1994). Pengantar Perancangan Kota (alih bahasa oleh Sussongko, dan Januar Hakim). Jakarta: Erlangga

Grewal dan Levy. (2008). Marketing. New York : McGraw Hill.

Krier, Leon. (1992). Architecture and Urban Design 1967-1992, Academy Edition. London.
Laurie, M. (1986). An Introduction to Landscape Architecture. New York: American Elsevier Publishing Co, Inc.

Lin, C.H. (2012). Effects of Cuisine Experience, Psychological Well-Being, And Self Health Perception on The Revisit Intention of Hot Springs Tourist. Journal of Hospitality \& Tourism Research,p.1-22

Muhammad Muqarrabin Ari, Denny Zulkaidy Wiwik Dwi Pratiwi. (2016). Evaluasi Dampak Penyediaan Taman-Taman Tematik Kota Bandung berdasarkan Persepsi Masyarakat Sekitar. Prosiding Temu Ilmiah IPLBI 2016

Nazaruddin, (1994). Penghijauan Kota. Jakarta: Swadaya.

New Gaik Ling. (2012). Faktor yang mempengaruhi kunjungan ulangan pelancong antarabangsa: Suatu ulasan. Malaysia. Malaysia Journal of Society and Space.

Vania Yodia dan Erwin Sudarma. 2015. Fleksibilitas Taman Hiburan Tematik terhadap Kedinamisan Tren dan Keterbatasan Lahan. Jurnal Sains dan Seni ITS, 4(2), G43-G46 
